\title{
Patricia Escola (1959-2019)
}

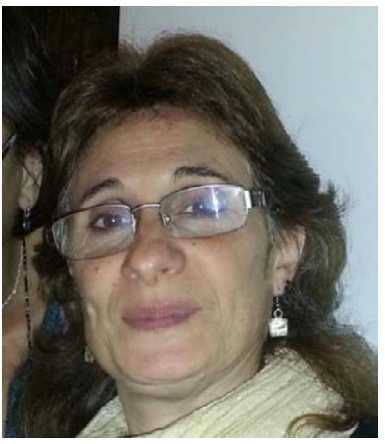

\section{(1) Nora Franco*}

¡Hola, Pato! Es muy difícil escribir esto ahora.

Nos conocimos en los primeros años de la carrera y juntas atravesamos las primeras materias. Éramos muy pocos alumnos en esa época. Juntas cursamos también las materias finales, las que nos permitían adentrarnos en la Arqueología, que era lo que en realidad nos gustaba. Fuimos juntas a nuestros primeros trabajos de campo, en Patagonia y Pampa, ya casi al final de la carrera (no había muchas oportunidades de participar en campañas en ese tiempo). Leímos el "Aschero" al mismo tiempo y, sobre esa base, nos pusimos a analizar y discutir los materiales de Pampa que debíamos estudiar, esperando a que Eduardo Crivelli los controlara y corrigiera, una vez por semana. Juntas cursamos Ergología y Tecnología, y conocimos al famoso Aschero, con sus preguntas disparadoras de ideas y el pizarrón con lo que íbamos diciendo. Poco después de ese momento Nora Flegenheimer nos introducía a ambas en la talla en una sesión que se dio en las Primeras Jornadas de Tipología Lítica. Después de terminar la carrera la vida nos llevó por carriles distintos. Vos empezaste a trabajar en Puna, de donde volviste fascinada. El interés por entender el lítico nos llevó a hacer cursos de talla y de lítico casi al mismo tiempo en Estados Unidos, donde el enfoque experimental que se daba era distinto del que predominaba en el país. Lo que aprendiste lo aplicaste no sólo para tus propias investigaciones en Puna sino que junto con Nora Flegenheimer y Cristina Bayón organizaron cursos de talla lítica en los que enseñaron estos nuevos enfoques y proporcionaron bibliografía a generaciones de nuevos "liticólogos". Junto con vos, Gabriela Guráieb y Teresa Civalero organizamos un curso de extensión en la UBA, en el que cada una dio sus distintas perspectivas en el análisis lítico, siempre basadas en un análisis profundo de los materiales. Con ellas también compartimos el dudoso mote de "Policía lítica", probablemente basado en esa forma de

* Instituto Multidisciplinario de Historia y Ciencias Humanas (IMHICIHU), CONICET / Facultad de Filosofía y Letras, Universidad de Buenos Aires (UBA). Saavedra 15 , $5^{\circ}$ piso (CP $\mathrm{C}_{1083} \mathrm{ACA}$ ) Ciudad Autónoma de Buenos Aires, Argentina. E-mail: nvfranc02008@gmail.com trabajo. La verdad es que ese creo que nos dolió a todas. $Y$ no quiero dejar de mencionar a los talleres de Horco Molle, donde entre todos y con Carlos ahí, pudimos preguntar nuestras dudas y compartir nuestras experiencias.

Los caminos distintos que seguimos nos separaron largo tiempo, con encuentros limitados a algunos cumpleaños, reuniones y/o Congresos, donde teníamos la oportunidad de ponernos a charlar durante momentos más o menos largos. Cada una, sin duda, se mantenía al tanto de lo que hacía la otra y leía atentamente los trabajos. Las áreas eran tan diferentes, pero así y todo siempre había tanto para pensar y aprender...

Afortunadamente los reencuentros vinieron después, con vos ya viviendo en Catamarca, con las reuniones organizadas en distintos lugares y, en los últimos tiempos, en casa de Cristina Bellelli y con un grupo de Whatsapp que disfrutábamos. Por supuesto, el lítico no era el foco de esas charlas ni mucho menos, ya que eran reuniones de amigas. El lítico y el mundo científico, siempre sobrevolaban esas reuniones, aterrizando a veces, claro. Ahí Pato luchamos con vos en lo que te tocó de enfermedad y tratamos de acompañar. La última vez que te vi personalmente fue en el CAELA, en Córdoba. Ahí vos ya pensabas que era tu último congreso y varias de nosotras insistimos en que lo pelearas. Afortunadamente allí tuviste tu merecido homenaje junto con Nora Flegenheimer y Cristina Bayón. ¡Y pudiste cantar, lo que te encantaba! Después de eso, no tuve ocasión de encontrarme con vos. La última charla en que te vi fue en una videollamada en que vos estabas en Catamarca con Cristina, Gabriela Guráieb y Tere Civalero y, por nuestra parte, Lizzie Pintar y yo estábamos en una sala en un Meeting, en Estados Unidos. iFue un muy lindo encuentro, en el medio de mucho ruido que había en el pasillo en el que estábamos con Lizzie para poder hablar! iQué fuerza que tenías todavía y qué fuerza tuviste hasta el final! El día que partiste nos tomó de sorpresa, aunque sabíamos que te habían internado. Es que un rato antes nos habías contestado en el chat grupal.

Fue duro pero afortunadamente, no fue demasiado largo para vos. Un golpe duro para todos y, en particular para Julián y Jorge, como el tiempo mostró después. 


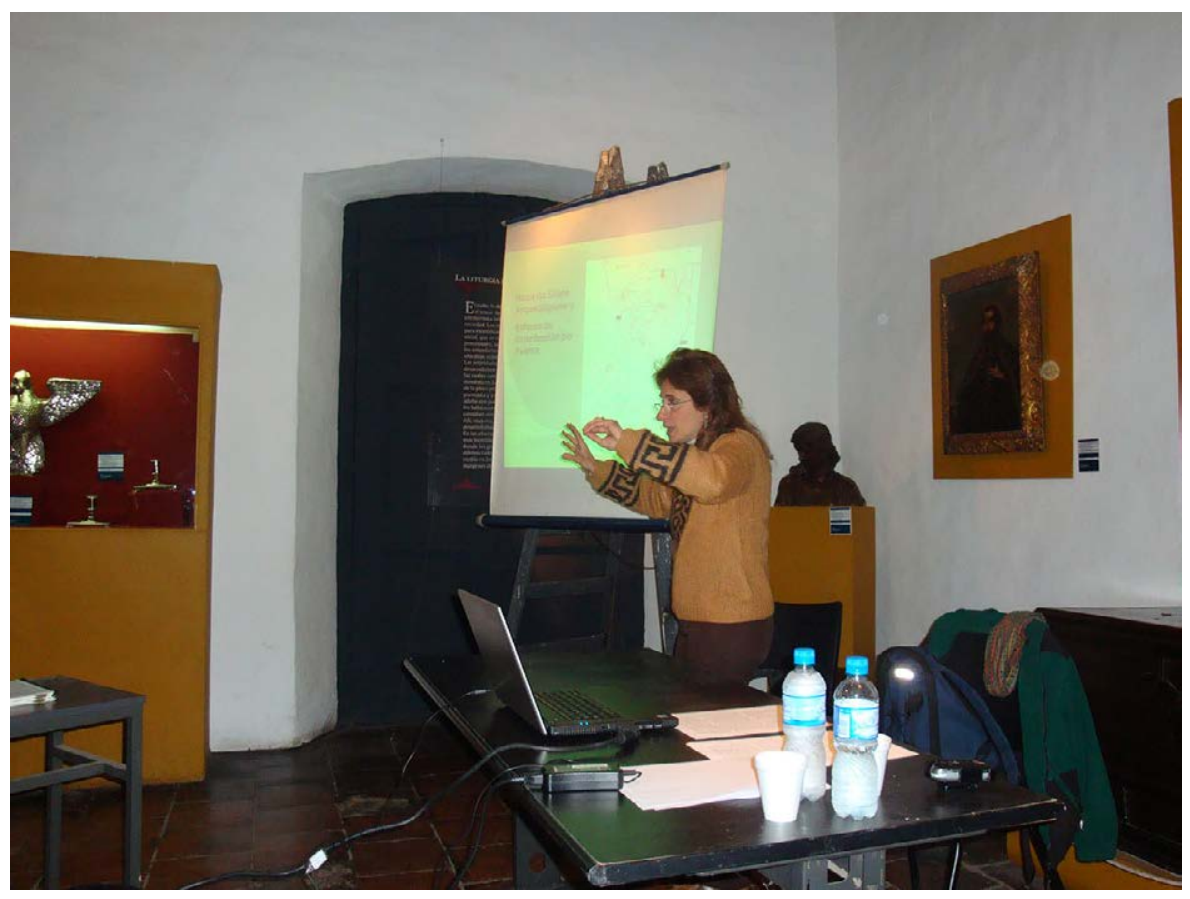

Pato Escola en una charla en Tucumán en el año 2009 (gentileza de Nora Flegenheimer).

En el mundo científico lo que hiciste no será olvidado por las generaciones posteriores, a cuya formación sin duda contribuiste. En lo personal, nosotras no te olvidaremos ni tampoco las personas con las que te encontraste en la vida. Fue conmovedor ver las fotos de los habitantes del lugar cuando llevaron tus cenizas.
Te fuiste Pato, muy pronto, pero siempre estarás adentro nuestro, con todo lo compartido juntas. ¡Hasta siempre, amiga! 